http://dx.doi.org/10.30681/23588403v14i0112

\title{
A AUSÊNCIA DE POLÍTICAS LINGUÍSTICAS PARA O ENSINO DE LÍNGUA INGLESA NA EDUCAÇÃO INFANTIL
}

\author{
Camila Souza de ANDRADE (UNESA/CEDERJ) ${ }^{1}$
}

Data de recebimento: $10 / 05 / 2020$

Data de aceite: 02/08/2020

\begin{abstract}
Resumo: O ensino de língua inglesa é inserido cada vez mais cedo nos anos de escolarização, pois vivemos em uma sociedade globalizada que está em constante contato com diversas culturas e línguas. Nesse contexto, a língua inglesa, que é tida como língua de comunicação universal, tornou-se pré-requisito para muitas tarefas e oportunidades de emprego. Diante disso, muitos responsáveis têm buscado cada vez mais escolas que ofertem o ensino de inglês a partir da Educação Infantil. Contudo, mesmo diante das expansões da oferta do ensino de inglês nas séries iniciais, no Brasil, ainda não tem política linguística que norteie esse ensino. Desta forma, a criação de uma política linguística voltada para o ensino de línguas para as séries iniciais é de suma importância para que o ensino dessas novas línguas aconteça de forma adequada e para que a aprendizagem dos estudantes seja alcançada. Por fim, o presente estudo pode contribuir para futuras pesquisas sobre políticas linguísticas e para implementação de futuras ações de políticas linguísticas para o ensino de línguas nas séries iniciais.
\end{abstract}

Palavras-chave: Educação Infantil. Ensino de Inglês. Políticas Linguísticas.

\begin{abstract}
English language teaching is increasingly inserted in the school years, as we live in a globalized society that is in constant contact with different cultures and languages. In this context, the English language, which is seen as a universal communication language, has become a prerequisite for many jobs and job opportunities. In view of this, many officials have increasingly sought schools that offer English teaching from early childhood education. However, even in the face of the expansion of the offer of teaching English in the early grades, in Brazil, there is still no Language Policy to guide this teaching. In this way, the creation of a linguistic policy aimed at the teaching of languages for the initial grades is of paramount importance for the teaching of these new languages to take place properly and for the learning of students to be achieved. Finally, the present study can contribute to future research on Language Policies and to the implementation of future actions of Language Policies for the teaching of languages in the initial grades.
\end{abstract}

Keywords. Early childhood education. Language Policy. Teaching English.

\section{Considerações iniciais}

\footnotetext{
${ }^{1}$ Mestre em Estudos de Linguagem pela Universidade Federal Fluminense (UFF). Professora da Universidade Estácio de Sá (UNESA) e Mediadora Presencial do CEDERJ. Niterói/ RJ/ Brasil. E-mail: csaletras@ gmail.com.
} 
No atual contexto escolar, observamos que o ensino de língua inglesa é iniciado cada vez mais cedo nos anos de escolarização. Esse fato ocorre, pois vivemos em uma sociedade globalizada que está ligada diretamente com diversas culturas e línguas. Nesse cenário, o inglês, que é conhecido por ser uma língua universal, tornou-se pré-requisito para muitas tarefas e oportunidades de emprego.

No Brasil, as políticas linguísticas para o ensino de línguas reconhecem os benefícios de oferecer o ensino de inglês na Educação Básica. Nesse sentido, os Parâmetros Curriculares Nacionais (PCN, 1998) destacam os fatores históricos para justificar a escolha do ensino de uma língua estrangeira:

\footnotetext{
Os fatores históricos estão relacionados ao papel que uma língua específica representa em certos momentos da história da humanidade, fazendo com que sua aprendizagem adquira maior relevância. A relevância é frequentemente determinada pelo papel hegemônico dessa língua nas trocas internacionais, gerando implicações para as trocas interacionais nos campos da cultura, da educação, da ciência, do trabalho etc. O caso típico é o papel representado pelo inglês, em função do poder e da influência da economia norte-americana. Essa influência cresceu ao longo deste século, principalmente a partir da Segunda Guerra Mundial, e atingiu seu apogeu na chamada sociedade globalizada e de alto nível tecnológico, em que alguns indivíduos vivem neste final do século. $O$ inglês, hoje, é a língua mais usada no mundo dos negócios, e em alguns países, como Holanda, Suécia e Finlândia, seu domínio é praticamente universal nas universidades. (p. 22-23)
}

Contudo, segundo as políticas linguísticas que norteiam o ensino de línguas, a oferta do ensino de língua inglesa é obrigatória a partir do $6^{\circ}$ ano do ensino fundamental séries finais. Ainda assim, observamos que várias instituições de ensino passaram a ofertar o ensino de inglês a partir da Educação Infantil, pois pensando no futuro de seus filhos, muitas famílias, matriculam as crianças em escolas que disponibilizam o ensino de língua inglesa em seus currículos a partir da Educação Infantil.

O pressuposto dessa pesquisa teve como propósito destacar os benefícios do ensino de inglês nos primeiros anos da infância e a importância de ter documentos oficiais que norteiem esse ensino.

Nessa perspectiva, entendemos que a produção de um artigo com vistas à realização de uma pesquisa bibliográfica qualitativa acerca da importância do inglês, do ensino de língua inglesa nas séries iniciais e da relevância da confecção de políticas linguísticas para o ensino de inglês nas séries iniciais é considerada válida no sentido de que os dados gerados poderão contribuir para o processo de confecção de uma política linguística voltada para o ensino de inglês nas séries iniciais. 


\section{A língua inglesa e seu status}

É sabido que o inglês é o idioma mais falado no mundo, entre nativos e não nativos da língua, fato este que colabora para que esta língua tenha um status diferente das demais línguas presentes no mundo, o status de língua global. Para que uma língua tenha o status de língua global é necessário que ela seja uma língua de suma importância nas relações econômicas, sociais e culturais.

Aprofundando a temática, Mufwene (2010) ressalta que para uma língua ter o status de língua global não basta ter o maior número de falantes e acrescenta que se esse fosse o critério o chinês seria considerado a língua global. Seguindo essa mesma diretriz, Rajagopalan (2015) afirma que não é apenas o número de falantes que determina se uma língua é global, mas sim ter "nítida presença assegurada". Isto é, ser uma língua que seja usada nas relações internacionais como meio de comunicação.

Uma língua torna-se mundial devido ao poder de seus falantes e no caso da língua inglesa ela contempla quatro poderes, a saber: político, tecnológico, econômico e cultural. O poder político surgiu através do colonialismo que contribuiu para a expansão da língua durante o século XVI; o tecnológico durante a Revolução Industrial nos séculos XVIII e XIX; o econômico através do crescimento dos Estados Unidos ultrapassando a Grã-Bretanha e por último, o cultural que se destacou no século XX (CRYSTAL, 2005; ANDRADE, 2016).

De acordo com Rajagopalan (2005, p.135), “a língua inglesa se encontra profundamente estabelecida como a língua-padrão do mundo, como parte intrínseca da revolução global das comunicações”. Convergindo com esse pensamento de que a língua inglesa é uma língua de uso global, Leffa (2006) postula que a comunidade que utiliza a língua inglesa para a comunicação "é maior do que qualquer categoria profissional ou país que fala inglês" (Leffa, 2006, p. 13). Para o autor, o inglês não é uma língua estrangeira, pois esta língua pertence ao mundo e não a um país específico.

Seguindo essa mesma diretriz, Leffa (2006) menciona que a língua inglesa como língua internacional pode ser vista de uma posição periférica ou central. O autor cita os estudos de Kachru, que propõe que o uso do inglês pode ser dividido em três grandes círculos: interno, externo e o em expansão. No círculo interno inserem-se os países em que o inglês é falado como língua nativa, são eles: Estados Unidos, Reino Unido, Canadá, Austrália e Nova Zelândia; no círculo externo estão os países em que o inglês é a segunda língua: Índia, Singapura, Malásia, África do Sul; por fim, o círculo em expansão que é constituído por 
países em que o inglês é utilizado como língua estrangeira, como: Brasil, China, Japão e Israel. Leffa (2006) ressalta também que o inglês como língua internacional seria mais utilizado nos países que pertencem ao terceiro círculo e que o circulo proposto por Kachru sugere que a evolução da língua inglesa concentra-se no circulo externo, ou seja, nos países onde o inglês é falado como segunda língua.

Acerca da temática do status da língua inglesa, compartilhamos do pensamento de Fernandez e Fogaça (2009) de que mais importante do que a denominação é o que a língua inglesa representa no atual cenário. E no atual cenário é necessário que os indivíduos aprendam a língua inglesa, pois ela passou a ser pré-requisito para muitos empregos, escolas, viagens e etc.

Diante desse cenário, reconhecemos que o aprendizado da língua inglesa é de suma importância na atualidade e por isso o ensino deste idioma passou a ser procurado cada vez mais cedo pelos responsáveis ampliando assim o número de escolas que ofertam o ensino deste idioma nas séries iniciais.

\section{O ensino de inglês para crianças}

É inegável que a aprendizagem de línguas estrangeiras é importante na sociedade globalizada em que vivemos, pois estamos em constante contato com pessoas de diversas culturas seja online ou offline. Sobre essa temática, os Parâmetros Curriculares Nacionais $(\mathrm{PCN})$ destacam que:

\footnotetext{
Em linhas gerais, o que a aprendizagem de uma Língua Estrangeira vai fazer é: aumentar o conhecimento sobre linguagem que o aluno construiu sobre sua língua materna, por meio de comparações com a língua estrangeira em vários níveis; possibilitar que o aluno, ao se envolver nos processos de construir significados nessa língua, se constitua em um ser discursivo no uso de uma língua estrangeira. (BRASIL, 1998, p. 28-29).
}

Saber se comunicar em pelo menos uma língua estrangeira (doravante LE) é primordial e o inglês, devido ao seu status de língua global, é ainda é o idioma mais procurado pelos pela família das crianças. Seguindo essa diretriz, Lightbown; Spada (2006) postulam que falar um segundo idioma ou ser bilíngue deixou de ser visto como um diferencial e, atualmente é visto como uma necessidade tanto para as crianças quanto para os adultos. Com isso, cada vez mais vem aumentando o número de escolas bilíngues e escolas que oferecem o ensino de língua inglesa na educação infantil aqui no Brasil. 
No que diz respeito ao ensino de LE para crianças, é fundamental que o processo ensino-aprendizagem de LE para crianças se inicie cada vez mais cedo. Reforçando essa ideia, Dimer e Soares (2012) afirmam que em pesquisas a área da neurociência divulgam que a idade ideal para o aprendizado de uma segunda língua ocorre nos primeiros dez anos de vida.

Convergentemente, Chaguri (2004) afirma que as crianças assimilam uma língua estrangeira com maior naturalidade quando começam cedo, visto que quanto mais cedo o inicio mais tempo dedicado ao aprendizado da língua alvo e sendo assim a criança acumulará mais conhecimento e de maneira sólida.

Ainda a respeito dos benefícios de iniciar o processo de aprendizagem de inglês na infância, Penfield e Roberts (1967 apud Dimer e Soares, 2012), afirmam que antes dos dez anos o cérebro apresenta seu ponto mais alto de plasticidade e na adolescência o cérebro não teria as mesmas capacidades, as mesmas perdidas gradativamente e que segundo alguns estudos, nunca mais serão obtidos.

Convergentemente, Lenneberg (1967, p.28) afirma que "a aprendizagem de uma língua estrangeira, é bem sucedida durante os primeiros anos da infância, após doze anos de idade todos teríamos dificuldades na aprendizagem de outro idioma”. Ademais, Gonçalves (2009) ressalta que uma das razões para o aprendizado de língua inglesa se tornar eficaz na vida de uma criança é devido a sua curiosidade.

Com base no que foi exposto, acreditamos que quanto mais cedo a criança iniciar o contato com a língua inglesa, maior será o rendimento dela no idioma. Porém, segundo Gonçalvez (2009), o ensino de língua estrangeira para crianças só é benéfico quando é inserido como algo leve e natural no dia-a-dia sem apressar o aprendizado dela e respeitando os aspectos emocionais e intelectuais de cada criança.

Chaguri (2004) salienta que nas séries iniciais o professor de inglês não deve cobrar e nem ensinar conteúdos gramaticais da língua inglesa, pois a apresentação desse novo idioma deve-se dar de maneira prazerosa para que a criança sinta-se motivada a aprender.

Diante disso, afirmamos que o processo de ensino e aprendizagem de inglês na Educação Infantil deve ser feito através de atividades lúdicas que despertem a curiosidade das crianças para que elas possam ser estimuladas e tenham sucesso em seu aprendizado. De acordo com Nunes (2004, apud Chaguri, 2004, p.4):

As atividades lúdicas têm o poder sobre a criança de facilitar tanto o progresso de sua personalidade integral, como o progresso de cada uma de suas funções psicológicas intelectuais e morais. Ademais, a ludicidade não influencia apenas as crianças, ela também traz vários benefícios aos adultos, os quais adoram aprender algo ao mesmo tempo em que se distraem (NUNES, 2004, ON-LINE). 
Sem políticas linguísticas voltadas para o ensino de inglês nas séries iniciais, os professores costumam encontrar desafios para ministrar as aulas de língua inglesa para as crianças. Dentre os desafios podemos destacar o seguinte questionamento: como apresentar o idioma para as crianças? Sobre essa temática, Chaguri (2004) afirma que o vocabulário é um dos principais fatores que temos que ter atenção ao trabalhar a LE nas séries iniciais. $\mathrm{O}$ autor postula que este deve ser aprendido pela criança através do uso de objetos ou com material audiovisual e para pronuncia é ótimo o uso de CDs o qual o aluno possa ouvir um nativo.

Para a apresentação da língua inglesa na Educação Infantil, os professores costumam usar flashcards, vídeos, músicas, jogos e objetos para que as crianças consigam internalizar os novos vocabulários no idioma. Sobre essa temática, o pesquisador Brown (2001, apud Chaguri, 2004, p.4) postula que quanto mais a criança é exposta a uma palavra, maior será a absorção da mesma. Sendo assim, as aulas de inglês para crianças devem ser lúdicas e interessantes, utilizando-se de jogos, músicas, entre outros que ajudarão na fixação da matéria (CHAGURI, 2004).

Em vista dos argumentos apresentados, afirmamos que o ensino de uma LE na infância é benéfico, pois pode contribuir no aumento do conhecimento sobre linguagem. Tendo em vista que o ensino de inglês nas séries iniciais é um fator positivo e que estamos cada vez mais cedo em contato com línguas no mundo globalizado em que vivemos, por que as políticas linguísticas de ensino de LE não inclui o ensino de línguas nas séries iniciais?

\section{Políticas Linguísticas para o ensino de línguas}

Segundo Calvet (2007), as línguas servem para possibilitar a comunicação, porém são também uma escolha política. O conceito de políticas linguísticas é recente, surgiu na segunda metade do século XX e está associado a abordagens que envolvem decisões acerca das línguas e da sociedade (CALVET, 2007). A política linguística pode ser definida como um conjunto de escolhas conscientes referentes às relações entre língua(s) e a sociedade (CALVET, 2002, 2007).

No Brasil, tradicionalmente, as políticas linguísticas enfatizam o ensino de línguas, inicialmente as línguas clássicas, grego e latim e, posteriormente, nas línguas modernas: francês, inglês, alemão, italiano e espanhol (LEFFA,1999). Contudo, esse ensino com o passar dos anos foi sofrendo uma depreciação no espaço escolar. 
Leffa (1999) destaca que foi durante o período do Império que se iniciou a decadência do ensino de línguas simultaneamente com o desprestígio crescente da escola secundária e menciona que apesar de não ter estudos e estatísticas sobre aspectos importantes que envolvam o ensino de línguas da época do Império, pode-se confirmar essa decadência através de leis, decretos e portarias que apontam uma queda gradual no prestígio do ensino das línguas LE no espaço escolar (LEFFA,1999).

Em 1892, com a reforma de Fernando Lobo, a carga horária destinada ao ensino de línguas reduziu ainda mais. Nesse período, o ensino da língua grega desaparece, a língua italiana não é oferecida ou torna-se facultativa e o inglês e o alemão passam a ser oferecidos de modo exclusivo; o aluno faz uma língua ou a outra, mas não as duas ao mesmo tempo (LEFFA, 1999).

Em 1931, ocorreram algumas mudanças no ensino de línguas tanto em relação ao conteúdo quanto em relação à metodologia. No que diz respeito ao conteúdo, priorizou-se às línguas modernas e esse fato ocorreu não devido ao aumento da carga horária escolar, mas por causa da diminuição da carga destinada ao ensino de latim. No que tange a metodologia, que foi onde ocorreu a grande mudança, introduzia o ensino da língua por meio da própria língua ao invés de trabalhar com a tradução (LEFFA, 1999).

Em 1942, ocorreu a reforma Capanema, que teve a capacidade de equiparar todas as modalidades de ensino médio. O ministro Capanema destacava que o ensino não deveria ser apenas voltado apenas aos aspectos instrumentais. Nesse contexto, o ensino médio foi dividido em dois ciclos; o primeiro denominado ginásio, com duração de quatro anos; o segundo tinha duas ramificações: uma denominada clássico que tinha foco no estudo de línguas clássicas e modernas e a outra denominada científico, que focava o estudo das ciências. Nesse cenário, os alunos no espaço escolar estudavam latim, francês, inglês e espanhol, e com isso, muitos terminavam o ensino médio lendo os autores nos originais (LEFFA, 1999).

Em 1961, foi criada a primeira Lei de Diretrizes e Bases da Educação (LDB) e inaugurou a descentralização do ensino no país. Para viabilizar este processo, criou-se o Conselho Federal de Educação que se encarregava de indicar até cinco disciplinas obrigatórias, cabendo aos Conselhos Estaduais de Educação complementar relacionar aquelas consideradas de caráter optativo.

No que tange ao ensino de língua estrangeira clássica, o latim, com raras exceções, foi retirado do currículo, enquanto o francês quando não era retirado, tinha uma redução em sua 
carga horária reduzida e o inglês permaneceu sem grandes alterações. Em 1971, foi publicada a Lei 5.692, de 11 de agosto de 1971 a qual reduz o ensino de doze anos para onze e introduz o primeiro grau com oito anos de duração e o segundo com três. ${ }^{2}$

No contexto de redução de um ano de escolaridade e com a necessidade de se introduzir a habilitação profissional, o ensino de LE teve a carga horária reduzida mais uma vez. Depois de um parecer do Federal de que a LE seria "dada por acréscimo", isto é, seria opcional de acordo com as condições de cada instituição a redução foi agravada. Em decorrência disso, Leffa (1999) ressalta que muitas instituições escolares retiraram as aulas de LE do Primeiro Grau e no Segundo Grau e ofereceriam cerca de uma hora por semana. Nesse período, vários alunos, principalmente do antigo supletivo, passaram pela educação básica sem terem visto pelo menos uma LE no espaço escolar.

Diante do que foi exposto, podemos constatar que o ensino de línguas vem sofrendo modificações e reduções de carga horária e opções de oferta de línguas no contexto escolar e, principalmente, que o ensino de LE nas séries iniciais não é mencionado. Atualmente, o ensino de línguas na educação básica é regido pelas seguintes Políticas Linguísticas: Lei de Diretrizes e Bases da Educação (LDB), Parâmetros Curriculares Nacionais (PCN), Orientações Curriculares para o Ensino Médio $\left(\mathrm{OCEM}^{3}\right)$ e Base Nacional Curricular Comum (BNCC).

\section{Políticas linguísticas atuais para o ensino de línguas}

Em 1996, foi publicada a nova LDB (Lei $n^{\circ}$ 9.394), esse documento torna obrigatório o ensino de pelo menos uma LE a partir da quinta série do Ensino Fundamental e, no Ensino Médio, o ensino de uma língua estrangeira obrigatória e uma segunda língua como optativa e não menciona o ensino de LE nas séries iniciais.

Com o propósito de complementar a LDB, pedagogos e especialistas elaboraram os Parâmetros Curriculares Nacionais (PCN) que são divididos em dois ciclos voltados ao ensino de línguas estrangeiras. De acordo com os PCN, a aprendizagem de uma língua estrangeira é

${ }^{2}$ Cabe aqui mencionar que nesse período houve um forte incentivo ao estudo do inglês, pois os laços de cooperação entre o EUA e o Brasil se estreitaram devido aos acordos entre o Ministério da Educação brasileira (MEC) e a Agência dos Estados Unidos para o Desenvolvimento Internacional (USAID).

${ }^{3}$ Não abordaremos as OCEM nesse trabalho, pois é um documento voltado apenas para o Ensino Médio. 
um direito de todo cidadão, conforme estipula a LDB e pela Declaração Universal dos Direitos Linguísticos (1996).

No que concerne aos PCN, eles são divididos em dois ciclos voltados ao ensino de línguas estrangeiras. De acordo com os PCN, a aprendizagem de uma língua estrangeira é um direito de todo cidadão, conforme estipula a LDB e pela Declaração Universal dos Direitos Linguísticos (1996). O PCN também não aborda a questão do ensino de LE para as séries iniciais, menciona somente o Ensino Fundamental II e o Ensino Médio.

Em 2016, a LDB passou por algumas reformulações, mas não foram positivas para o ensino de línguas. Essas novas reformulações não possibilitou uma maior oferta de línguas, pelo contrário, a nova LDB torna obrigatório o ensino do inglês a partir do sexto ano e torna opcional a oferta de uma segunda LE, sendo preferencialmente o espanhol. Cabe aqui ressaltar que mesmo com a crescente oferta do ensino de LE nas séries iniciais e diante da globalizada em que vivemos a LDB não inclui o ensino de LE na Educação Infantil e nem no Ensino Fundamental I.

Em 2017, foi lançada a BNCC, nela excluiu-se o ensino de todas as outras LE, priorizando apenas o ensino de inglês. Sustentando um discurso baseado na importância do status do inglês como uma língua de comunicação internacional, tanto a LDB (2016) quanto a BNCC (2017) enfatizam o ensino dessa língua "para a inserção dos sujeitos no mundo globalizado" (BRASIL, 2017, p.244). Sobre essa temática, concordamos que o ensino de LI é importante devido ao seu status de língua de comunicação global. Entretanto, discordamos do fato de tornar apenas o ensino de um único idioma obrigatório.

No que concerne ao ensino de línguas na Educação Básica, o ideal é que fossem ofertadas pelo menos duas LE nas escolas, inclusive nas séries iniciais. Estamos cada vez mais inseridos em um mundo interconectado no qual ter competência comunicativa em LE é visto como condição sine qua non. Ademais, as crianças cada vez mais cedo estão em contato com LE sejam através de jogos, músicas e/ou vídeos no youtube.

Tendo em vista os aspectos observados, afirmamos que é necessário que as Políticas Linguísticas para o ensino de línguas na Educação Básica passem por reformulações para que possam abarcar as séries iniciais e para que possam promover o plurilinguísmo na escola e não apenas a imposição de apenas um idioma.

\section{Considerações finais}


$\mathrm{Na}$ sociedade globalizada em que vivemos, onde estamos cada vez mais cedo em contato com outras línguas e culturas, a aprendizagem de pelo menos uma LE além de sua língua materna passou a ser pré-requisito para muitas atividades. Diante desse cenário, os responsáveis cada vez mais estão em busca de escola que ofertem o ensino de inglês, devido ao seu status de língua de comunicação global, desde a Educação Infantil.

A partir das observações apresentadas ao longo deste trabalho, acreditamos que o ensino de inglês pode ser benéfico nas séries iniciais, pois nessa fase as crianças têm a capacidade de aprender uma LE com mais eficácia do que quando mais velha. Contudo, esse ensino precisa ser de forma lúdica e prazerosa para que assim, os discentes possam absorver melhor a nova língua.

No decorrer de décadas, várias políticas linguísticas foram reformuladas sob uma perspectiva de garantir o ensino de LE. Porém, percebemos que ao longo dos anos a carga horária destinada ao ensino de LE foi sendo reduzida bem como a quantidade de LE a serem oferecidas. Ademais, constatamos que em nenhum momento foi citado o ensino de LE nas séries iniciais nem nas novas reformulações que ocorreram recentemente.

Desta forma, a criação de uma política linguística voltada para o ensino de LE para as séries iniciais é de suma importância para que o ensino dessas novas línguas aconteça de forma adequada e para que a aprendizagem dos estudantes seja alcançada. Pois, através de uma política linguística que norteie o ensino de LE na Educação Infantil e Ensino Fundamental 1, os professores terão diretrizes que poderão guiar seu trabalho.

Por fim, acreditamos que a presente pesquisa pode contribuir para futuros estudos acerca de políticas linguísticas e para implementação de futuras ações de políticas linguísticas para o ensino de línguas nas séries iniciais.

\section{Referências bibliográficas}

ANDRADE, C.S. Representações linguísticas de alunos de uma escola pública acerca do processo de ensino-aprendizagem de língua inglesa. Anais do VII SAPPIL - Estudos de Linguagem. 2016.

BRASIL. Ministério da Educação, Secretaria da Educação Média e tecnológica. Lei de Diretrizes e Bases da Educação (LDB). Brasília, DF, 1996.

Ministério da Educação, Secretaria da Educação Média tecnológica. Parâmetros curriculares nacionais: ensino fundamental (PCNs). Brasília, DF, 1998. 
Ministério da Educação, Secretaria da Educação Média tecnológica Base Nacional Comum Curricular. Brasília, DF, 2017.

CALVET, L. J. Sociolinguística: uma introdução crítica. São Paulo: Parábola, 2002.

.As políticas linguísticas. São Paulo: Parábola Editorial, 2007.

CHAGURI, J. P. A Importânica da Língua Inglesa nas Séries Iniciais do Ensino Fundamental. In: O DESAFIO DAS LETRAS, 2., 2004, Rolândia. Anais... Rolândia: FACCAR, 2005. 08 f. ISSN: 1808-2548

CRYSTAL, D. A revolução da linguagem. Rio de Janeiro: Jorge Zahar Ed., 2005.

DIMER, D.L., SOARES, A. O ensino de língua inglesa para crianças. In: Revista Ensiqlopédia, v.9, nº1, 2012.

FERNANDEZ, C. M.; FOGAÇA, F. C. Inglês como língua internacional na universidade: rejeição e objeto de desejo. Linguagem \& Ensino, Pelotas, v.12, n.1, p.195-225, jan./jun. 2009

GONÇALVES, M. R. A necessidade de incentivar a aprendizagem da língua inglesa desde a infância. Revista Eletrônica de Divulgação Científica da Faculdade Don Domênico. 2a Edição, 2009.

LEFFA, V. J. O ensino de línguas estrangeiras no contexto nacional. Contexturas: APLIESP, n. 4, p. 13-24, 1999.

Língua estrangeira hegemônica e solidariedade internacional. In: KARWOSKI, Acir Mário; BONI, Valéria de Fátima Carvalho Vaz (Orgs.). Tendências contemporâneas no ensino de inglês. União da Vitória, PR: Kaygangue, 2006, p. 10-25.

LENNEBERG, E. Biological foundations of language. New York: Wiley, 1967.

LIGHTBOWN,P; SPADA, M. N. How languages are learned. Oxford: Oxford University Press, 2006.

RAJAGOPALAN, K. A geopolítica da língua inglesa e seus reflexos no Brasil: por uma política prudente e propositiva. In: LACOSTE, Y (Org.). A geopolítica do inglês. São Paulo: Parábola Editorial, 2005.

. Políticas públicas, línguas estrangeiras e globalização: a universidade brasileira em foco. In: ROCHA, C. H; et al. (Orgs.). Políticas linguísticas, ensino de línguas e formação docente: desafios em tempos de globalização e internacionalização. São Paulo: Editora Pontes, 2015.

MUFWENE, S. Globalization, global English, and world English(es) : myths and facts. In: The handbook of language and globalization. 2010. 